University of Wollongong

Research Online

Faculty of Engineering and Information

Faculty of Engineering and Information

Sciences - Papers: Part B

Sciences

2018

Driver intention based coordinate control of regenerative and plugging braking for electric vehicles with in-wheel PMSMs

Wenfei Li

University of Wollongong,w1015@uowmail.edu.au

Haiping Du

University of Wollongong, hdu@uow.edu.au

Weihua Li

University of Wollongong, weihuali@uow.edu.au

Follow this and additional works at: https://ro.uow.edu.au/eispapers1

Part of the Engineering Commons, and the Science and Technology Studies Commons

Research Online is the open access institutional repository for the University of Wollongong. For further information contact the UOW Library: research-pubs@uow.edu.au 


\title{
Driver intention based coordinate control of regenerative and plugging braking for electric vehicles with in-wheel PMSMs
}

\author{
Abstract \\ Electric vehicles have been the focus of the automotive industry in recent years. However, relatively small \\ driving range of electric vehicles makes it not be broadly adopted in the market. Regenerative braking is \\ one of the most effective ways to extend the endurance of electric vehicles. To sufficiently utilise the \\ regenerative braking of electric vehicles and explore the potential of the electric motor plugging braking \\ capability to simplify the braking system structure and reduce the cost, a new braking strategy based on \\ the driver's braking intention and motor working characteristics is proposed. Driver's braking intention is \\ classified as the emergency braking and the normal braking. In the case of normal braking, model \\ predictive control (MPC) is used to express driver's braking intention. By adjusting the weight of the MPC \\ cost function, different braking intentions can be achieved. This strategy is able to achieve as much as \\ possible braking energy recovery without violating the driver's braking intention. In the case of the \\ emergency braking, the sliding mode based optimal slip ratio control is adopted and it is able to obtain \\ the shortest braking distance. In order to validate the effectiveness of the proposed approach, numerical \\ simulations on a quarter-vehicle braking model are tested.

\section{Disciplines} \\ Engineering | Science and Technology Studies

\section{Publication Details} \\ W. Li, H. Du \& W. Li, "Driver intention based coordinate control of regenerative and plugging braking for \\ electric vehicles with in-wheel PMSMs," IET Intelligent Transport Systems, vol. 12, (10) pp. 1300-1311, \\ 2018.
}




\title{
Driver intention based coordinate control of regenerative and plugging braking for electric vehicles with in-wheel PMSMs
}

\author{
Wenfei $\mathrm{Li}^{1 *}$, Haiping $\mathrm{Du}^{1}$, Weihua $\mathrm{Li}^{2}$ \\ ${ }^{1}$ School of Electrical, Computer \& Telecommunications Engineering, university of wollongong, Wollongong \\ 2522, Australia \\ ${ }^{2}$ School of Mechanical, Materials and Mechatronic Engineering, university of wollongong, Wollongong 2522, \\ Australia \\ *w1015@uowmail.edu.au
}

\begin{abstract}
Electric vehicles have been the focus of the automotive industry in recent years. However, relatively small driving range of electric vehicles makes it not be broadly adopted in the market. Regenerative braking is one of the most effective ways to extend the endurance of electric vehicles. To sufficiently utilize the regenerative braking of electric vehicles and explore the potential of electric motor plugging braking capability to simplify the braking system structure and reduce the cost, a new braking strategy based on the driver's braking intention and motor working characteristics is proposed. Driver's braking intention is classified as the emergency braking and the normal braking. In case of normal braking, model predictive control (MPC) is used to express driver's braking intention. By adjusting the weight of MPC cost function, different braking intentions can be achieved. This strategy is able to achieve as much as possible braking energy recovery without violating the driver's braking intention. In case of the emergency braking, the sliding mode based optimal slip ratio control is adopted and it is able to obtain the shortest braking distance. In order to validate the effectiveness of the proposed approach, numerical simulations on a quarter-vehicle braking model are tested.
\end{abstract}

\section{Introduction}

Active Brake System such as Anti-lock braking system (ABS), Electronic brake force distribution (EBD) and Electronic stability programme (ESP) has become a standard configuration of many vehicle. ABS is able to prevent the locking of wheels. Thus avoiding uncontrolled skidding. EBD is able to automatically regulate the distribution of brake force to each wheel according to motion state of each wheel [1]. EBD is a derived auxiliary function from ABS [2]. ESP is a computerized technology that improves a vehicle's stability by detecting and reducing loss of traction. ESP interposes only when it detects a possible loss of steering control [1]. All these studies focus on vehicle stability at the emergency braking situation. When vehicle braking on the longitudinal direction in the case of normal braking, the kinetic braking energy recovery of the vehicle should be considered.

With the rising concern on global environmental and energy issue, electric vehicles have been the focus of the automotive industry in recent years because electric vehicles have the advantages of high efficiency and zero emission. However, limited by the battery technology, battery electric vehicles are still not competitive enough compared with conventional vehicles in the aspects of driving range and cost [3]. Research shows that about one third to one half of the driving energy will be dissipated during braking in urban driving [4]. And electric vehicles have a great advantage in terms of energy saving at driving cycles with low average speeds and frequent stops [5]

In order to extend the driving range of electric vehicles, regenerative braking is widely used in electric vehicles. In the regenerative braking mode, kinetic energy can be recovered into electric energy instead of being wasted as heat. Thus, it employs the motor back electromotive force
(EMF) in the braking process and achieves dual goals of the electric braking and the energy regeneration simultaneously [6]. In order to improve energy recovery, many researches have been proposed [7]-[10]. In [11], three blended braking strategies, 'Eco', 'Sport' and 'Safety (Motor Priority)', are proposed to achieve a balance between braking performance, driving comfort and energy recovery rate. In [12]-[16], the transmission ratio adjusting is as a research object to improve the energy recovery. Downshift during regenerative braking helps to improve the energy efficiency of electric vehicles. An off-line calculation and on-line look-up table method is adopted to obtain the optimal downshift point to get the best energy efficiency of electric vehicles during the regenerative braking. It cooperatives control of regenerative braking and hydraulic braking to ensure brake safety during downshift process [17]. In [18], an HEV equipped with an automated manual transmission (AMT) is chosen as the study platform. Two downshifting strategies based on rules and DP algorithm are proposed for improving energy conservation during regenerative braking process. However, few studies have been done to improve energy recovery by studying the characteristics of electrical machines.

Permanent magnet synchronous motor (PMSM) is widely used in electric vehicles with the advantages of high power density and high efficiency [19]. PMSM has two main modes of operation: motoring and braking. Motoring always requires electric power flow into the PMSM. On the other hand, braking can occur in two distinct ways: if electric power flows out of the PMSM when braking, then this mode of operation is referred to as regenerative braking; In this case, the motor is a generator. It can convert kinetic energy into electrical energy. If electric power flows into the PMSM when braking, then this mode of operation is referred to as plugging braking. PMSM is driven by threephase voltage source inverter (VSI). Normally, the three- 
phase VSI is controlled by field oriented control (FOC) or six-step commutation [20]. Compared to six-step commutation, FOC has higher efficiency and smaller current ripple [21]. The PMSM can also be used to achieve regenerative braking. When the back EMF is lower than the battery voltage in regenerative braking, the boost converter circuit is necessary to guide the current back to the battery [22][23]. However, the maximum regenerative braking torque of PMSM is limited by many factors. For example, it depends on the maximum braking torque provided by the motor, inverter capacity, and motor speed etc.

In order to achieve the braking energy recovery without affecting the braking performance, various blended braking systems have been proposed. The most often used blended braking system is to combine the regenerative braking with a friction braking system, where the friction braking system is used to provide large braking torque. In [24], a combination of electro-hydraulic brake (EHB) system and regenerative brake system (RBS) is proposed. EHB is able to provide large braking torque when RBS is not able to provide enough braking torque at low speed. In [25], a blended system of electro-mechanical brake (EMB) and RBS is proposed. Compared to [26], it has more fast response. For the blended braking system control, cooperative control of RBS and other friction braking systems can be classified as series and parallel types. In the parallel strategy, the friction braking system is the same as in conventional vehicles, and the regenerative torque is added into the friction braking system proportionately. In the series strategy, the friction braking torque can be modulated, and the overall braking torque is controlled to meet the driver demand [7]. However, this blended braking system makes vehicle braking system complex and also increases cost.

In fact, PMSM is able to work at plugging braking mode. Plugging braking is to drive the motor in the reverse direction. Thus when the back EMF is not enough to generate the required braking torque in low speed, the electric power can be drawn out of the battery to assist the back EMF. It can be seen that either the electric power from the batteries or the back EMF of the motor can generate a braking torque to decelerate the motor [10] and the plugging braking is an effective method to provide a fast stop. In [8], plugging braking is used to make subway train stop in a fast way. In [9], an elevator is fast stopped through plugging braking. The drawback of plugging braking is that it produces a lot of heat during the process of plugging braking. However, the braking system works at plugging braking mode only when the regenerative braking torque is not able to satisfy the requirement of braking torque and it will not last for long time, so it will not produce too much heat. Another drawback of plugging braking is that it consumes energy, which will shorten the electric vehicles driving range. In order to extend the electric vehicles driving range, the plugging braking mode should be avoided as much as possible.

In case of emergency braking, the braking distance is the most important indicator. At this condition, the energy recovery and regenerative braking characteristics of motor can be ignored. However, the braking characteristics of motor should be considered for improving the energy recovery and electric vehicles driving range in the normal braking. The relationship between pedal displacement and braking force is considered in braking condition. In [19], the ANFIS has been used to identify driver's braking intention through 1200 sets of data. However, driver's braking intention is a subjective factor and is related to driver's driving habits. It is difficult to accurately quantify. When taking a brake action, driver cannot take the detailed characteristics of motor into consideration. For example, driver cannot know when the PMSM will switch from regenerative braking mode to plugging braking mode. Thus an appropriate control strategy needs to be developed to enable the needed braking action through the control of electric motor only.

In this paper, driver's braking intention is classified as the emergency braking and the normal braking. A braking strategy integrated characteristic of motor and driver's braking intention is proposed for the normal braking condition. MPC with constraints is first time introduced to obtain the relationship between driver's braking intention and braking torque. It is able to avoid PMSM working at plugging braking mode as much as possible without violating the driver's braking intention. In the case of the emergency braking, sliding mode based optimal slip ratio control is designed to obtain the shortest braking distance.

The rest of the paper is organized as follows. In Section 2, the vehicle braking system model is introduced. It includes the vehicle braking dynamics model under different brake conditions and characteristics of PMSM. In Section 3, the whole control diagram is introduced. It includes the power control system and the proposed braking strategy. The simulation results are presented in Section 4. Finally, conclusions are given in Section 5.

\section{System model}

\subsection{Braking control of PMSM}

Because PMSM has the characteristics of high power density and high efficiency [4], PMSM is selected to drive the vehicle wheel as an in-wheel motor. The control system of PMSM is shown in the Fig.1.

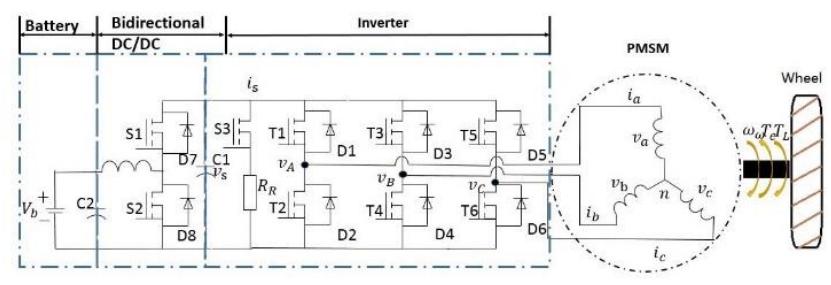

Fig. 1. Sketch of the control circuit of PMSM

As shown in the Fig. 1, the control system includes PMSM, bidirectional DC-DC converter, three-phase VSI, external resistor and the corresponding controllers. The bidirectional DC-DC converter is used to boost battery voltage to drive PMSM and make battery voltage have more choices. It is also able to achieve energy recovery to battery when motor works at regenerative braking mode. The external resistor is used to consume kinetic braking energy when the Battery's SoC exceeds safe operating range such as Battery's SoC exceeds $90 \%$. The three-phase VSI is used to transfer DC voltage to AC voltage and drive PMSM. The VSI consists of three identical legs consisting of two switches and two diodes each. Each leg of the VSI is operated with a pulse width modulated switch duty ratio to produce a balanced 
three-phase output which is given as the input to the electric machine. Both of the switches in the same leg cannot be turned $\mathrm{ON}$ at the same time, as it would short the input voltage. Thus the nature of operation of the two switches in the same leg is complementary. The DC-side of the power inverter is connected to a DC power source with bus capacitance.

In order to achieve more energy recovery, the dynamic characteristics of motor should be analyzed. The dynamic equation of the PMSM model in terms of phase variables can be expressed as [3]:

$\left[\begin{array}{c}v_{a} \\ v_{b} \\ v_{c}\end{array}\right]=\left[\begin{array}{ccc}R_{s} & 0 & 0 \\ 0 & R_{s} & 0 \\ 0 & 0 & R_{s}\end{array}\right]\left[\begin{array}{c}i_{a} \\ i_{b} \\ i_{c}\end{array}\right]+\left[\begin{array}{c}\frac{d \psi_{a}}{d t} \\ \frac{d \psi_{b}}{d t} \\ \frac{d \psi_{c}}{d t}\end{array}\right]$

$\left[\begin{array}{l}\psi_{a} \\ \psi_{b} \\ \psi_{c}\end{array}\right]=\left[\begin{array}{lll}L_{a a} & L_{a b} & L_{a c} \\ L_{b a} & L_{b b} & L_{b c} \\ L_{c a} & L_{c b} & L_{c c}\end{array}\right]\left[\begin{array}{l}i_{a} \\ i_{b} \\ i_{c}\end{array}\right]+\left[\begin{array}{l}\psi_{a m} \\ \psi_{b m} \\ \psi_{c m}\end{array}\right]$

where $v_{a}, v_{b}, v_{c}$ - are the instantaneous three-phase stator voltages.

$R_{s}$ - is the armature resistance.

$i_{a}, i_{b}, i_{c}$ - are the instantaneous three-phase stator currents.

$\psi_{a}, \psi_{b}, \psi_{c}$ - are the instantaneous three-phase flux linkages.

$L_{a a}, L_{b b}, L_{c c}$ - self-inductance of stator windings.

$L_{a b}, L_{a c}, L_{c b}$ - mutual inductance.

$\psi_{a m}, \psi_{b m}, \psi_{c m}$ - are the instantaneous three-phase PM flux linkages.

For the motor controller design, the PMSM model is usually transferred to $\mathrm{d}-\mathrm{q}$ reference frame through Park's transformation. The Park's transformation $\boldsymbol{T}_{\boldsymbol{a b c} / \boldsymbol{d q}}$ is:

$\boldsymbol{T}_{\boldsymbol{a b c} / \boldsymbol{d q}}=$

$\sqrt{\frac{2}{3}}\left[\begin{array}{ccc}\cos \left(P_{n} \theta\right) & \cos \left(P_{n} \theta-\frac{2 \pi}{3}\right) & \cos \left(P_{n} \theta+\frac{2 \pi}{3}\right) \\ -\sin \left(P_{n} \theta\right) & -\sin \left(P_{n} \theta-\frac{2 \pi}{3}\right) & -\sin \left(P_{n} \theta+\frac{2 \pi}{3}\right) \\ \frac{\sqrt{2}}{2} & \frac{\sqrt{2}}{2} & \frac{\sqrt{2}}{2}\end{array}\right]$

where $\theta$ is the rotor mechanical angular position. Through the Park's transformation, the steady-state physics of the electric machine are indicated by the equivalent $\mathrm{d}$-axis and q-axis circuit diagrams shown in Fig. 2(a).

Electrical model of PMSM in the $d-q$ reference frame can be expressed as in Eqs (4)(5) [3]:

$\left\{v_{d}=R_{s} i_{d}-P_{n} \omega L_{q} i_{q}\right.$

$\left\{v_{q}=R_{s} i_{q}+P_{n} \omega\left(L_{d} i_{d}+\psi_{f}\right)\right.$

$T_{e}=\frac{3}{2} P_{n} i_{q}\left(i_{d}\left(L_{d}-L_{q}\right)+\psi_{f}\right)$

where $v_{d}, v_{q}$ are $\mathrm{d}$ and $\mathrm{q}$-axis terminal voltages; $i_{d}, i_{q}$ are $\mathrm{d}$ and q-axis armature currents; $L_{d}, L_{q}$ are $\mathrm{d}$ and q-axis inductances; $R_{S}$ is armature resistance; $\omega$ is electrical angular velocity; $\psi_{f}$ is permanent magnet flux linkage; $P_{n}$ is number of pole pairs; $T_{e}$ is motor torque. For the non-salient outer rotor PMSM, $L_{d}=L_{q}$, then Eq (5) can be written as:

$T_{e}=\frac{3}{2} P_{n} i_{q} \psi_{f}$

The control input to the system is a duty cycle vector with coordinates $u_{d}$ and $u_{q}$, and the effect of the power converter on the electric machine is to impose a voltage vector with coordinates satisfying

$v_{d}=u_{d} v_{s}, v_{q}=u_{q} v_{s}$

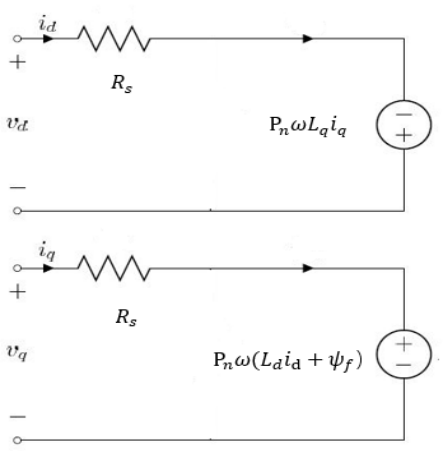

$a$

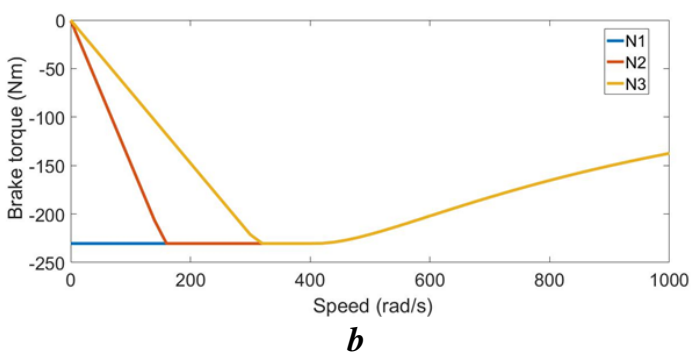

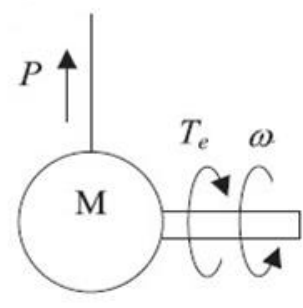

Regenerative braking

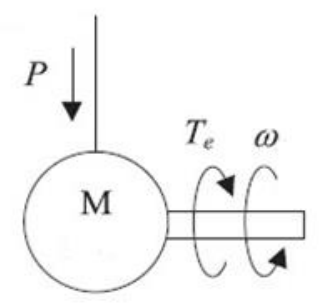

Plug braking

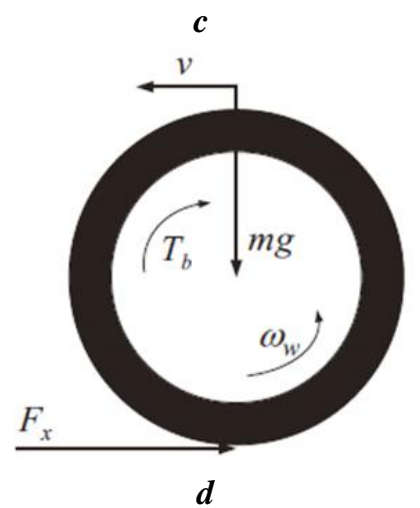

Fig. 2. Vehicle wheel and motor model (a) Steady-state equivalent circuit models in the $\mathrm{d}$ and $\mathrm{q}$ axes of PMSM, (b) Graphical visualization of numerical solutions of various constrained optimization problems, (c) Power and state of PMSM for regenerative braking and plugging braking, (d)Wheel dynamic model

where $v_{s}$ is the bus voltage. Assuming that the power inverter is lossless, it follows that source power $v_{s} i_{s}$ must match electric machine power $v_{d} i_{d}+v_{q} i_{q}$, in which case $i_{s}=u_{d} i_{d}+u_{q} i_{q}$

These operational limits are characterized by the constant parameters $U_{\max }$ and $I_{\max }$.

$\left\|u_{d q}\right\|=\sqrt{u_{d}^{2}+u_{q}^{2}} \leq U_{\max }$ 
$\left\|i_{d q}\right\|=\sqrt{i_{d}^{2}+i_{q}^{2}} \leq I_{\max }$

where $U_{\max }$ and $I_{\max }$ are fixed parameters. Table I lists the parameter values for the electric machine system considered in this section.

The torque-speed capability of the electric machine system for forward rotation in its braking capability region and its regenerative braking capability region are determined by solving the following optimization problems.

N1) for feasible $\omega \geq 0$,

minimize $T$

subject to (4)-(10), $T \leq 0$

N2) for feasible $\omega \geq 0$,

$$
\left\|u_{d q}\right\| \leq U_{\max },\left\|i_{d q}\right\| \leq I_{\max }
$$

minimize $T$

subject to (4)-(10), $T \leq 0, i_{s} \leq 0$

N3) for feasible $\omega \geq 0$,

$$
\left\|u_{d q}\right\| \leq U_{\max },\left\|i_{d q}\right\| \leq I_{\max }
$$

minimize $i_{s}$

subject to (4)-(10), $T \leq 0, i_{s} \leq 0$

$$
\left\|u_{d q}\right\| \leq U_{\max },\left\|i_{d q}\right\| \leq I_{\max }
$$

N1 defines the boundary of forward braking capability. N2 defines the boundary of forward regenerative braking capability. N3 defines the regenerative braking torque that corresponds to maximize battery-pack recharge current. As shown in Fig.1, the source power is presented as $v_{s} i_{s} . v_{s}$ is the bus voltage and is positive number. $i_{s}$ is the bus current. When $i_{s}$ is positive, it means that the electric power is transferred from power system to PMSM. When $i_{s}$ is negative, it means that the electric power is transferred from PMSM to power system and the PMSM works at regenerative braking mode. When the motor takes the maximum braking torque, the $i_{s}$ could be positive (motor works at plugging braking mode) or negative (motor works at regenerative braking mode). In order to find the maximum braking torque the motor can provide at the corresponding speed, $i_{s}$ should not be limited. So the information of the current direction is not given in $\mathrm{N} 1$. When the current is negative, it means that motor works at regenerative braking mode. It means that the electric power is transferred from PMSM to power system. The smaller the value of $i_{s}\left(i_{s} \leq 0\right)$, the greater the absolute value of the current $\left|i_{s}\right|$. When $i_{s} \leq 0$ (regenerative braking mode), $\left|i_{s}\right|$ is the recharge current. So the recharge current is maximized when minimizing the current $i_{s}$.

The numerically computed solutions to these optimization problems are shown in Fig. 2(b). From this Fig. 2(b), it can be seen that there are three separate regions. The plugging braking is between the torque axis and the solution to N2.

The two motor braking states are shown in Fig. 2(c), where the electric power is transferred from kinetic energy to the electric energy stored in batteries during the process of regenerative braking, and the electric power is transferred from the batteries to kinetic energy during the process of plugging braking.

\subsection{Vehicle braking dynamics model}

When the vehicle is at different braking conditions, the tireroad force is different. Normally, the braking operation can be classified into two conditions: emergency braking condition and normal braking condition. During the normal braking, the friction between the tire and the road can be retreated as rolling friction. During the emergency braking, the tire-road coefficient of friction is mainly related with wheel slip ratio and the main objective is to stop the vehicle as quick as possible with the shortest stopping distance. Thus it is necessary to take different vehicle dynamic models under different braking conditions.

At the emergency braking condition, a quarter-vehicle braking model [13], which is simple but eff ective (see Fig. 2(d)), is used and only the longitudinal force is considered in this paper. The vehicle braking dynamic model during the emergency braking condition is shown in the Fig. 2(d):

In the case of emergency braking, the tire-road force is much greater than air resistance. The air resistance can be ignored at the emergency braking condition. The vehicle wheel rotation speed is mainly affected by three factors: braking torque, vehicle gravity, tire-road friction. The dynamics of the vehicle and wheel models can be expressed as:

$$
\begin{aligned}
& \mathrm{J} \dot{\omega}_{\omega}=-T_{e}+R F_{x} \\
& \mathrm{~m} \dot{v}=-F_{x} \\
& F_{x}=\mu(\lambda) m g \\
& T_{t}=R F_{x} \\
& v=R \omega_{v} \\
& \lambda=\frac{\omega_{v}-\omega_{\omega}}{\omega_{v}}
\end{aligned}
$$

where $\mathrm{R}$ is the effective wheel radius, $\mathrm{J}$ is the moment of inertia of the wheel, $T_{e}$ is the braking torque, $F_{x}$ is the longitudinal tire force, $m$ is total mass of the quarter vehicle, $v$ is the longitudinal velocity of the vehicle, $\omega_{\omega}$ is the angular velocity of the wheel, $\omega_{v}$ is the angular velocity of the vehicle. $\mu(\lambda)$ is the longitudinal friction coefficient of the tire, $\lambda$ is the wheel slip ratio. $T_{t}$ is the torque provided by ground friction. In this paper, the tire model used is based on the tire friction model developed by Burckhardt and Reimpell (1993). It is shown below [13]:

$\mu(\lambda)=C_{1}\left(1-e^{-c_{2} \lambda}\right)-C_{3} \lambda$

where $C_{1}, C_{2}$ and $C_{3}$ are constants for different road conditions. $C_{1}$ is the maximum value of the friction curve, $C_{2}$ represents the shape of the friction curve and $C_{3}$ is the difference between the peak value of the friction curve and the value when the slip ratio is 1 . From this equation, it can be seen that tire-road friction coefficient is a function of wheel slip ratio.

In the case of normal braking, the tire-road friction can be seen as rolling friction and the braking objective is to decelerate the vehicle to a given speed. The vehicle speed is mainly affected by three factors: braking torque, tire-road rolling friction and aerodynamic drag. The dynamics of the vehicle can be expressed as:

$\mathrm{m} \dot{v}=-\frac{\mathrm{T}_{\mathrm{b}}}{\mathrm{R}}-\mathrm{C}_{\mathrm{r}} \mathrm{mg}-\frac{1}{2} \rho A \mathrm{C}_{\mathrm{d}} v^{2}$

where $C_{r}$ is coefficient of rolling resistance. $C_{d}$ is the aerodynamic drag coefficient. $A$ is the frontal area. $\rho$ is the air density. At the right side of this equation, the first term is the motor braking torque acting on the vehicle, the second term is tire-road rolling friction, the third term is the air resistance. For controller design, equation (18) can be written as follows:

$\dot{v}=b u+f$

where $b=-\frac{1}{m R}, u=T_{b}, f=-\mathrm{C}_{\mathrm{r}} \mathrm{g}-\frac{1}{2 m} \rho A \mathrm{C}_{\mathrm{d}} v^{2}$. And $f$ can be seen as the disturbance of the system. The control method will be introduced in the following part. 


\section{Control structure}

In this part, the whole control system will be introduced. It includes three parts, the DC-DC converter controller, vector controller and braking controller. The whole braking control diagram is shown in the Fig. 3(a).

First, the braking intention is identified based on the brake pedal displacement and speed of brake pedal. Then braking strategy is chosen. In the case of emergency braking, sliding mode based optimal slip ratio control is used to achieve the best vehicle braking performance. In the case of normal braking condition, MPC with constraints is used to achieve driver's braking intention. Then corresponding command braking torque is sent to vector controller. The vector controller is used to control three-phase inverter and make PMSM achieve the command braking torque. The bidirectional DC-DC controller is used to keep bus voltage at a constant voltage and achieve the energy exchange between battery and PMSM. The details will be shown in following parts.

\subsection{Braking strategy design}

Because the braking objectives are different under different braking conditions, different braking strategies are designed. The proposed braking control strategy is shown in the Fig. 3(b).

As shown in Fig. 3(b), the braking situation is classified as emergency braking and normal braking based on the speed of brake pedal $\left(v_{t}\right)$ and the brake pedal displacement $\left(d_{t}\right)$. According to reference [19], when the change rate of brake pedal is bigger than $120 \mathrm{rad} / \mathrm{s}^{2}$ or the brake pedal displacement is bigger than $90 \%$ of the maximum brake
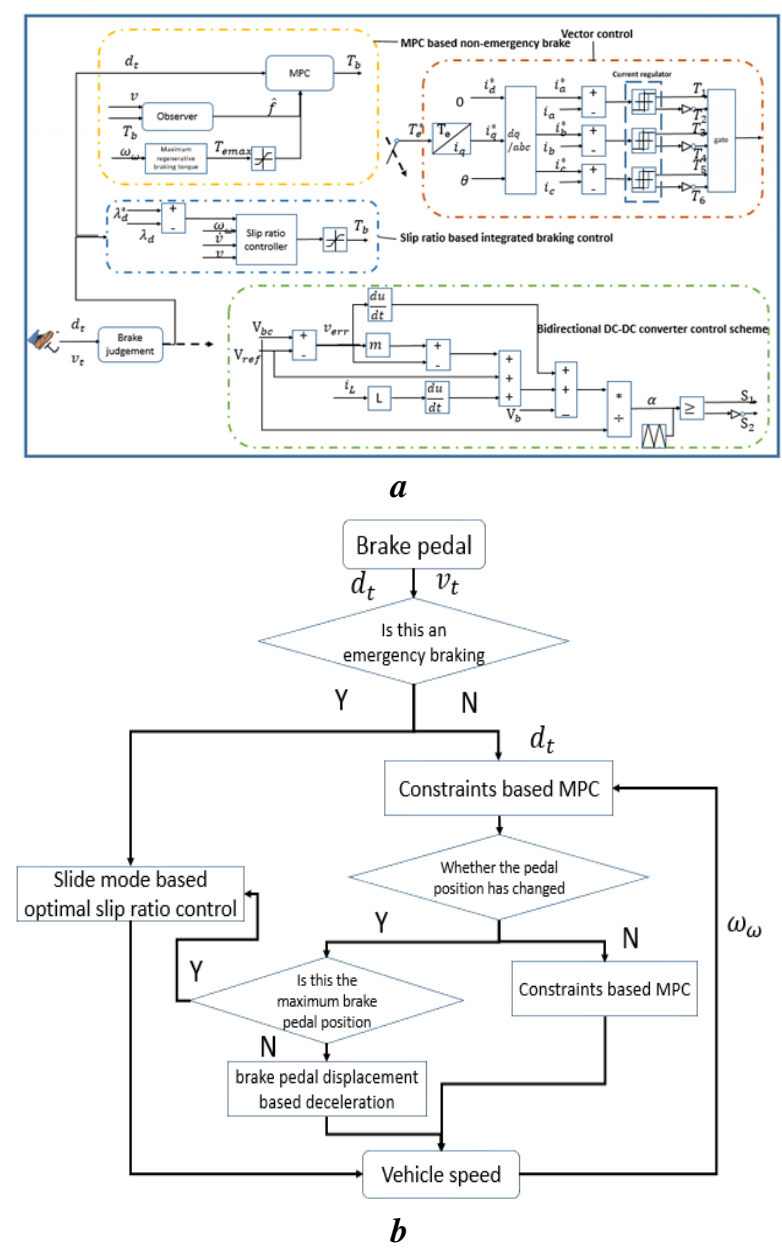

Fig. 3 control diagram and strategy (a) Whole control diagram, (b)

Braking control strategy. pedal displacement, the braking action is regarded as emergency braking. Otherwise, the braking action is regarded as normal braking. The Battery's SoC has also important impact on absorbing the regenerative energy. The safe operating range of Battery's SoC is 30\% 90\%. If the Battery's SoC exceeds $90 \%$, the motor should not work at regenerative braking mode. When the desired braking torque makes motor work at regenerative braking mode at the corresponding speed, the bidirectional DC-DC converter will not work and the S3 will be closed (as shown in Fig.1). Then the kinetic braking energy can be consumed by external resistor. This strategy avoids overcharging.

In the case of emergency braking, the shortest braking distance is the brake target. When the wheel slip ratio is at optimal slip ratio, the vehicle can obtain the maximum braking force and the shortest braking distance. So the target is to make wheel slip ratio follow the optimal slip ratio. Sliding mode control has faster and better tracking performance than other tracking control algorithm. In order to make wheel slip ratio fast and accurate track the optimal slip ratio and obtain the shortest braking distance, sliding mode control is adopted. In the case of normal braking, the traditional braking strategy is to make vehicle deceleration follow the brake pedal position. And the relationship between brake pedal position and vehicle deceleration is usually designed as linear. However, this brake control strategy does not take motor characteristics and energy recovery into account. Because driver does not know the details of the motor characteristics, the driver cannot make the optimal brake strategy for improving energy recovery based on motor characteristics. The proposed MPC brake control strategy is designed based on the motor characteristics and driver's braking intention. In the case of normal braking, the driver usually has two intentions. One is to make vehicle stop and another one is to reduce the vehicle speed to a certain speed. The driver usually puts the brake pedal on a certain displacement $\left(d_{t}\right)$. When the braking intention is reached, brake pedal returns to its original position $\left(d_{t}=0\right)$. And the maximum regenerative braking torque can be obtained based on the motor angular velocity $\left(\omega_{\omega}\right)$. It is used as a constraint for the MPC. Then the braking torque is calculated through the constraints based MPC. This braking torque is used to reduce vehicle speed. In this braking strategy, the vehicle can avoid PMSM working at plugging mode and recover as much as possible energy. If the brake pedal position has no change, the braking torque will follow the braking command from the constraints based MPC. When the driver feels the vehicle deceleration cannot satisfy his braking intention, the driver will further step on the brake pedal. Then the braking torque will follow the braking command from the brake pedal displacement based deceleration brake strategy. If the brake pedal displacement is larger than the $90 \%$ of the maximum displacement, it means that the driver wants to make the vehicle stop as soon as possible. Then the braking situation switches to emergency braking. The braking control strategy details will be introduced in the following parts.

The heat generated by plugging braking affects the permanent magnets. However, the plugging braking is only a small part of the whole braking process (as shown in Fig 2(b)). The proposed braking control strategy (constraints 
based MPC) is designed to avoid motor working at plugging braking (as shown in section 3.1 in the paper). It is able to effectively reduce the heat generated by plugging braking. Then the heat generated by plugging braking can be ignored.

\subsubsection{Extended disturbance observer}

In order to eliminate uncertain disturbance and for the further MPC design, the extended observer is used to estimate the disturbance which is caused by tire-road friction and other factor as shown in Eq (19). In the case of normal braking, vehicle wheel is rolling and tires are not slipping. The vehicle speed can be obtained through wheel encoder. The equation can be rewritten as:

$\dot{\mathrm{x}}=\mathrm{bu}+\mathrm{f}$

where $\mathrm{x}$ is the vehicle speed $v$. To estimate the disturbance $\mathrm{f}$, an extended observer is designed as:

$\dot{\hat{x}}=b u+\hat{\sigma}+\frac{\alpha_{1}}{\varepsilon}(x-\hat{x})$

$\dot{\hat{\sigma}}=\frac{\alpha_{2}}{\varepsilon^{2}}(x-\hat{x})$

where $\hat{x}$ is the estimated value of $x$. $\hat{\sigma}$ is the estimated value of $f$.

$\frac{1}{\varepsilon}=\left\{\begin{array}{c}100 t^{3} 0 \leq t \leq 1 \\ 100 \quad t>1\end{array}\right.$

$\alpha_{1}, \alpha_{2}$ are positive real numbers. And $s^{2}+\alpha_{1} s+\alpha_{2}$ satisfy the condition of Hurwitz. The convergence proof procedure of the designed extended observer $\left(\lim _{t \rightarrow \infty} \hat{x}=\right.$ $x, \lim _{t \rightarrow \infty} \hat{\sigma}=f$ ) is shown as follows:

First, we make

$\boldsymbol{\eta}=\left[\begin{array}{ll}\eta_{1} & \eta_{2}\end{array}\right]^{T}$

where

$$
\eta_{1}=\frac{x-\hat{x}}{\varepsilon} \quad \eta_{2}=f-\hat{\sigma}
$$

then $\mathrm{Eq}$ (23) can be written as:

$\varepsilon \dot{\eta}_{1}=\dot{x}-\dot{\hat{x}}=\eta_{2}-\alpha_{1} \eta_{1}$

$\varepsilon \dot{\eta}_{2}=\varepsilon \dot{f}-\alpha_{2} \eta_{1}$

They can be rewritten as state-space function:

$\varepsilon \dot{\boldsymbol{\eta}}=\overline{\boldsymbol{A}} \eta+\varepsilon \overline{\boldsymbol{B}} \dot{f}$

(25)

where

then

$$
\overline{\boldsymbol{A}}=\left[\begin{array}{ll}
-\alpha_{1} & 1 \\
-\alpha_{2} & 0
\end{array}\right] \quad \overline{\boldsymbol{B}}=\left[\begin{array}{l}
0 \\
1
\end{array}\right]
$$

$|\lambda I-\overline{\boldsymbol{A}}|=\left[\begin{array}{cc}\lambda+\alpha_{1} & -1 \\ \alpha_{2} & \lambda\end{array}\right]=0$

then

$\lambda^{2}+\alpha_{1} \lambda+\alpha_{2}=0$

Through choosing $\alpha_{1}, \alpha_{2}$ make $\overline{\boldsymbol{A}}$ satisfy Hurwitz. Then there exists a symmetric positive definite matrix $\mathbf{P}$ satisfying Lyapunov:

$\overline{\boldsymbol{A}}^{\boldsymbol{T}} \boldsymbol{P}+\boldsymbol{P} \overline{\boldsymbol{A}}+\boldsymbol{Q}=0$

where $\boldsymbol{Q}$ is an arbitrary symmetric positive definite matrix.

We define Lyapunov function as:

$V_{0}=\varepsilon \boldsymbol{\eta}^{\boldsymbol{T}} \boldsymbol{P} \boldsymbol{\eta}$

(29)

then

$$
\dot{V}_{0} \leq-\boldsymbol{\eta}^{\boldsymbol{T}} \boldsymbol{Q} \boldsymbol{\eta}+2 \varepsilon\|\boldsymbol{P} \overline{\boldsymbol{B}}\|\|\boldsymbol{\eta}\||\dot{f}|
$$

$\dot{V}_{0} \leq-\lambda_{\min }(\boldsymbol{Q})\|\boldsymbol{\eta}\|^{2}+2 \varepsilon\|\boldsymbol{P} \overline{\boldsymbol{B}}\|\|\boldsymbol{\eta}\||\dot{f}|$

where $\lambda_{\min }(\boldsymbol{Q})$ is the minimum eigenvalue of $\mathbf{Q}$. In order to make $\dot{V}_{0} \leq 0,\|\boldsymbol{\eta}\|$ should satisfy:

$\|\boldsymbol{\eta}\| \leq \frac{2 \varepsilon\|\boldsymbol{P} \bar{B}\||\dot{f}|}{\lambda_{\min }(Q)}$ when $\mathrm{Eq}(32)$ is satisfied, $\lim _{t \rightarrow \infty} \hat{x}=x, \lim _{t \rightarrow \infty} \hat{\sigma}=f$ and the disturbance is estimated. After the disturbance is estimated, the estimated disturbance is used as compensation item added to the braking torque controller.

\subsubsection{Normal braking control strategy}

In this paper, the MPC is used to build the relationship between driver's brake intentions and braking torque. For controller design, Eq (19) can be written as discrete function as follows:

$v(k+1)=v(k)+a_{f}(k) T_{s}$

$a_{f}(k)=b u(k)+f(k)$

where $b=-\frac{1}{m R}, u=u_{m p c}-\frac{\hat{\sigma}}{b}, f=-\mathrm{C}_{\mathrm{r}} \mathrm{g}-\frac{1}{2 m} \rho A \mathrm{C}_{\mathrm{d}} v^{2}, T_{s}$ is the sampling time, $u_{m p c}$ is the predictive control and $\hat{\sigma}$ is the estimated disturbance through extended disturbance observer. When the estimated item $\frac{\widehat{\sigma}}{b}$ is added to the controller, the disturbance $f$ is approximately compensated, then $\mathrm{Eq}(33)$ can be rewritten as:

$v(k+1)=v(k)+T_{s} b u_{m p c}$

By choosing state vector $x_{m}(k)=v(k)$, input vector $u_{m p c}(k)$, output vector $\mathrm{y}_{\mathrm{m}}(\mathrm{k})=\mathrm{v}(\mathrm{k})$, then the state-space model is given by:

$x_{m}(k+1)=A_{m} x_{m}(k)+B_{m} u_{m p c}(k)$

$y_{m}(k)=C_{m} x_{m}(k)$

where $A_{m}=1 ; B_{m}=T_{s} b ; C_{m}=1$.

Then the predictive state-space can be seen (38). Where $N_{p}$ is the prediction horizon; $N_{c}$ is the control horizon; Then the output can be written as (39).

$\boldsymbol{Y}=\boldsymbol{F} x_{m}(k)+\boldsymbol{\phi} \boldsymbol{U}$

(39)

where

$$
\begin{aligned}
& \boldsymbol{Y}=\left[y_{m}(k+1 \mid k)^{T} \quad \ldots \quad y_{m}\left(k+N_{p} \mid k\right)^{T}\right]^{T} \\
& \boldsymbol{U}=\left[\begin{array}{lll}
u_{m p c}(k)^{T} & \ldots & u_{m p c}\left(k+N_{c}-1\right)^{T}
\end{array}\right]^{T} \\
& \boldsymbol{F}=\left[\begin{array}{c}
C_{m} A_{m} \\
C_{m} A_{m}^{2} \\
C_{m} A_{m}^{3} \\
\vdots \\
C_{m} A_{m}^{N_{p}}
\end{array}\right] \\
& \boldsymbol{\phi}=\left[\begin{array}{ccccc}
C_{m} B_{m} & 0 & 0 & \cdots & 0 \\
C_{m} A_{m} B_{m} & C_{m} B_{m} & 0 & \cdots & 0 \\
C_{m} A_{m}^{2} B_{m} & C_{m} A_{m} B_{m} & C_{m} B_{m} & \cdots & 0 \\
\vdots & \cdots & \cdots & \cdots & \cdots \\
C_{m} A_{m}^{N_{p}-1} B_{m} & C_{m} A_{m}^{N_{p}-2} B_{m} & C_{m} A_{m}^{N_{p}-3} B_{m} & \cdots & C_{m} A_{m}^{N_{p}-N_{c}} B_{m}
\end{array}\right]
\end{aligned}
$$

The optimal control vector over the future horizon can be obtained by minimizing the following cost function:

$\mathrm{J}=\left(\boldsymbol{R}_{\boldsymbol{v}}-\boldsymbol{Y}\right)^{T}\left(\boldsymbol{R}_{\boldsymbol{v}}-\boldsymbol{Y}\right)+\boldsymbol{U} \overline{\boldsymbol{R}} \boldsymbol{U}$

where $\boldsymbol{R}_{\boldsymbol{v}}$ is the reference vehicle speed. If there is no clear speed requirement, $\boldsymbol{R}_{\boldsymbol{v}}$ can be designed as 0 . If there is clear speed requirement, such as cruise or the vehicle drives at speed limit section, it can be set up as the desired speed; $\boldsymbol{Y}$ is the measured vehicle speed; $\boldsymbol{U}$ is the braking torque; $\overline{\boldsymbol{R}}$ is the weight of braking torque in the cost function.

According to

$\frac{\partial J}{\partial \boldsymbol{U}}=0$

$\boldsymbol{U}$ can be calculated as:

$\boldsymbol{U}=\left(\boldsymbol{\phi}^{\boldsymbol{T}} \boldsymbol{\phi}+\overline{\boldsymbol{R}}\right)^{-\mathbf{1}} \boldsymbol{\phi}^{\boldsymbol{T}}\left(\boldsymbol{R}_{\boldsymbol{v}}-\boldsymbol{F} x_{m}(k)\right)$

In our research, the receding horizon control is adopted and

$$
\begin{gathered}
x_{m}(k+1 \mid k)=A_{m} x_{m}(k)+B_{m} u_{m p c}(k) \\
x_{m}(k+2 \mid k)=A_{m} x_{m}(k+1 \mid k)+B_{m} u_{m p c}(k+1)=A_{m}^{2} x_{m}(k)+A_{m} B_{m} u_{m p c}(k)+B_{m} u_{m p c}(k+1) \\
x_{m}(k+3 \mid k)=A_{m}^{3} x_{m}(k)+A_{m}^{2} B_{m} u_{m p c}(k)+A_{m} B_{m} u_{m p c}(k+1)+B_{m} u_{m p c}(k+2) \\
\vdots \\
x_{m}\left(k+N_{p} \mid k\right)=A_{m}^{N_{p}} x_{m}(k)+A_{m}^{N_{p}-1} B_{m} u_{m p c}(k)+A_{m}^{N_{p}-N_{c}} B_{m} u_{m p c}\left(k+N_{c}-1\right)
\end{gathered}
$$


only the first element of the calculated vector $\boldsymbol{U}$ is used as the control signal.

In this paper, we make $\overline{\boldsymbol{R}}$ to be related with the brake pedal displacement. The relationship between the weight of braking torque $\overline{\boldsymbol{R}}$ and the brake pedal displacement $d_{t}$ is designed as:

$\bar{R}=C_{f} \cot \left(d_{t} p i / 2\right)$

where $C_{f}$ is a coefficient, which is designed based on the value of $\phi^{T} \phi . d_{t}$ is at $0 \% \sim 100 \%$, where $0 \%$ means that there is no brake action and $100 \%$ means that the brake pedal displacement is the maximum displacement. According to the characteristics of the cotangent function, we can know that when the brake pedal displacement $\left(d_{t}\right)$ is big, $\overline{\boldsymbol{R}}$ will be small. It means that the main optimization target is the vehicle speed. In this situation, the braking torque is big and the vehicle deceleration is big. When the brake pedal displacement is small, $\overline{\boldsymbol{R}}$ will be big. It means that the main optimization target is braking torque. In this situation, the braking torque is small and the vehicle deceleration is small. For example when $d_{t}=0 \%, \overline{\boldsymbol{R}}$ is a big value and $\boldsymbol{U}$ is close to 0 , vehicle speed keeps at a certain speed in this situation. When $d_{t}=100 \%, \bar{R}$ is 0 and $\boldsymbol{U}=U_{\max }$. In this situation, the vehicle speed will be reduced as quick as possible. These relationships match with the driver's natural driving habits.

In the design of MPC, $U_{\text {max }}$ is limited by many factors. In this paper, we take solutions of $\mathrm{N} 2$ as constraint for $\boldsymbol{U}$. Based on this design, it makes vehicle motor work at regenerative braking mode at the whole braking process. In order not to make the passengers feel uncomfortable, the braking deceleration should be less than $5 \mathrm{~m} / \mathrm{s}^{2}$ at the normal braking [19]. So the input of the system should satisfy following condition:

$a_{f} \leq 5 \mathrm{~m} / \mathrm{s}^{2}$

Then according to Eq (44), the $T_{d \max }$ can be calculated:

$T_{\text {dmax }} \leq \frac{5-\hat{\sigma}}{b}$

And then the constraint for MPC design is summarized as:

$U_{\max } \leq \min \left(T_{\text {rmax }}, T_{d \max }\right)$

Based on the cost function (40) and constraint (46), $\boldsymbol{U}$ can be calculated from the MPC design. The calculated braking torque is transferred to $i_{q}$ through (6). And through park's transformation equation (3), the desired phase current $i_{a}^{*}, i_{b}^{*}, i_{c}^{*}$ can be obtained. Then vector controller drive the inverter and make PMSM produce the desired braking torque.

Furthermore, when driver feels the deceleration cannot satisfy her/his requirement, the driver will further step on the brake pedal. In this situation, the brake pedal displacement based deceleration braking strategy will be considered. In this case, the relationship between the brake pedal displacement and vehicle deceleration is designed as linear. According to [17], the braking deceleration should be less than $5 \mathrm{~m} / \mathrm{s}^{2}$, the relationship between the brake pedal displacement and vehicle deceleration is designed as:

$a_{f}=5 d_{t}$

As shown in equation (47), the desired braking deceleration is $5 \mathrm{~m} / \mathrm{s}^{2}$ when the $d_{t}$ is $100 \%$. It is able to meet the requirement of linear relationship and will not make the passengers feel uncomfortable.
Then the braking torque can be calculated as:

$\boldsymbol{U}=\frac{a_{f}-\widehat{\sigma}}{b}$

Similarly, the braking torque is transferred to the drive signal

of inverter through vector controller.

\subsubsection{Emergency braking control strategy}

In the emergency situation, driver will make the brake pedal displacement more than $90 \%$ of the maximum brake pedal displacement or the change rate of the brake pedal is faster than $120 \mathrm{rad} / \mathrm{s}^{2}$ [21]. When the vehicle takes emergency braking, the tire-road friction coefficient is mainly related with wheel slip ratio as described in Section 2.2. When the wheel slip ratio is at the optimal slip ratio, the tire-road friction coefficient is the maximum friction coefficient. In this paper, we assume that the optimal slip ratio is known and 0.2 is treated as the optimal slip ratio $\left(\lambda_{d}\right)$ at the wet cobble road. Then sliding mode control is used to make the wheel slip ratio track the optimal slip ratio. The sliding surface is selected as:

$\mathrm{S}=\mathrm{e}$

where $\mathrm{e}$ is the difference between the real slip ratio $\lambda$ and the optimal slip ratio $\lambda_{d}$ : e $=\tilde{\lambda}=\lambda-\lambda_{d}$. Based on (11)(16), the è can be derived as follow:

$\dot{\mathrm{e}}=\dot{\tilde{\lambda}}=\dot{\lambda}=\left(\frac{R \omega_{\omega}}{v^{2}}+\frac{m R^{2}}{J v}\right) \dot{v}+\frac{R u}{J v}$

In this paper, we assume that the vehicle velocity $v$ and the acceleration $\dot{v}$ can be obtained through sensor measurement or other estimated algorithm. Then the command braking torque can be designed as:

$u=-\frac{c J v}{R}\left(\lambda-\lambda_{d}\right)-\frac{J \omega_{\omega}}{v} \dot{v}-m R \dot{v}$

where $c$ is a positive constant; The Lyapnove function is defined as:

$\mathrm{V}=\frac{1}{2} S^{2}$

Then

$\dot{\mathrm{V}}=S \dot{S}=-c \tilde{\lambda}^{2} \leq 0$

Thus the system is stable and $\lim _{t \rightarrow \infty} \tilde{\lambda}=0 \lim _{t \rightarrow \infty} \lambda=\lambda_{d}$. The wheel slip ratio will approach the optimal slip ratio, and the wheel can obtain the maximum braking force. The vehicle can obtain the shortest brake distance.

\subsection{Power system control}

\subsubsection{Bidirectional DC-DC control}

Dynamic evolution control has been utilized in [24]. The basic idea of dynamic evolution control is to reduce the error state by forcing the error state to follow a specific path, which ensures that the error state goes to zero as time goes by. This specific path is named as dynamic evolution path. With the selected evolution path being an exponential function, the value of the dynamic characteristic of the system will decrease exponentially to zero by

$Y=Y_{o} e^{-h t}$

where $Y$ is the dynamic characteristic of the system. $Y_{o}$ is the initial value of $Y . h$ is a design parameter specifying the rate of evolution and is a positive number.

The dynamic evolution function of this controller can be written as

$\frac{d Y}{d t}+h Y=0$ 
A schematic diagram of the bidirectional DC-DCconverter is shown in Fig. 1. Because the power converter switches are operated in a complementary way, it is sufficient to find out the control law in the boost mode of operation only. Based on the state-space average model, the voltage and current dynamics of the boost mode of operation are given by

$V_{b}=L \frac{d i}{d t}+v_{s}(1-\alpha)$

$\mathrm{C} \frac{d v_{S}}{d t}=i_{L}(1-\alpha)-\frac{v_{S}}{R}$

where $L$ is the inductance, $C$ is the capacitance, $R$ is the load resistance, $V_{b}$ is the battery voltage, $i_{L}$ is the inductor current, $v_{s}$ is the bus voltage, and $a$ is the duty cycle. Rearranging (54), the output voltage of the converter can be written as

$v_{s}=V_{b}+\alpha v_{s}-L \frac{d i}{d t}$

In power-electronic application, $Y$ can be selected as a function of error voltage or error current. By referring to the previous work [6], the selected $Y$ is a linear function of error voltage

$Y=k v_{\text {err }}$

where $k$ is a positive coefficient and $v_{e r r}$ is the error voltage

$v_{e r r}=V_{r e f}-v_{s}$. Substituting (59) into (55) yields

$k \frac{d v_{e r r}}{d t}+(\mathrm{h} k-1) v_{\text {err }}+V_{\text {ref }}=v_{S}$

$k \frac{d v_{e r r}}{d t}+(\mathrm{h} k-1) v_{\text {err }}+V_{\text {ref }}=V_{b}+\alpha v_{s}-L \frac{d i}{d t}$

Solving for $\alpha$, the obtained duty cycle $\alpha$ is given by

$\alpha=\frac{k \frac{d v_{e r r}}{d t}+(h k-1) v_{e r r}+L \frac{d i}{d t}+V_{r e f}-V_{b}}{v_{s}}$

then $\alpha$ is calculated. then the duty cycle signal is sent to drive the $S_{1}$ and $S_{2}$.

\subsubsection{Inverter vector control}

In the vector control scheme, the desired brake torque is transferred to $q$-axis current through equation (6). Through park' transformation, the d, q-axis currents transfer to a, b, c-axis currents. Then the actual measured current is forced to track the reference current within a hysteresis band. The switching frequency and peak-to-peak current ripple are governed by the width of the hysteresis band. Since the vector control has the advantages of simple to implement, fast transient response, direct limitation of device current, and practical insensitivity to machine parameters, it is widely adopted by the PMSM motor drive for EV [13]. Then the vector control is adopted to make PMSM produce the desired brake torque in this paper. The control scheme is shown in the Fig. 3.

\section{Numerical Simulations}

In order to verify the effectiveness of the proposed brake strategy, the proposed brake strategy is tested by the simulations. The system parameters are listed in Table 1 and the parameters of the tire-road model are listed in Table 2. In this paper, we take a quarter-vehicle as a research model. Quarter-vehicle mass is $365 \mathrm{~kg}$. The maximum braking torque of motor is the solution of N1. Through the gear, the maximum braking torque of motor is expanded by 10 times at the corresponding speed.

Table 2 Parameters of the tire-road model for various surfaces.

\begin{tabular}{cccc}
\hline Surface condition & $\mathrm{C}_{1}$ & $\mathrm{C}_{2}$ & $\mathrm{C}_{3}$ \\
\hline Cobble wet & 0.4004 & 33.708 & 0.1204 \\
\hline
\end{tabular}

Table 1 System parameters

\begin{tabular}{|c|c|c|c|}
\hline Symbol & Property & Value & Units \\
\hline$\psi_{f}$ & $\begin{array}{l}\text { Permanent magnet } \\
\text { flux linkage }\end{array}$ & 0.192 & $\mathrm{~Wb}$ \\
\hline$P_{n}$ & Number of pole pairs & 4 & - \\
\hline $\mathrm{R}_{s}$ & Armature resistance & 0.4 & $\Omega$ \\
\hline $\mathrm{m}$ & Vehicle mass & 1460 & $\mathrm{~kg}$ \\
\hline$R$ & Wheel radius & 0.3 & $\mathrm{~m}$ \\
\hline A & Rated capacity & 8.1 & Ah \\
\hline SoC & Initial state-of-charge & 75.75 & $\%$ \\
\hline$J$ & $\begin{array}{l}\text { Quarter-vehicle } \\
\text { moment of inertia }\end{array}$ & 36 & $k g * m^{2}$ \\
\hline $\mathrm{Gr}$ & Gear ratio & 10:1 & - \\
\hline$K_{p}$ & Proportional gain & 5 & - \\
\hline$K_{i}$ & Integral gain & 1 & - \\
\hline $\mathrm{A}$ & Front area & 2.2 & $m^{2}$ \\
\hline$\rho$ & Air density & 1.29 & $\mathrm{~kg} / \mathrm{m}^{3}$ \\
\hline$C_{r}$ & $\begin{array}{l}\text { Rolling resistance } \\
\text { coefficient }\end{array}$ & 0.016 & - \\
\hline$C_{d}$ & $\begin{array}{l}\text { Aerodynamic drag } \\
\text { coefficient }\end{array}$ & 0.28 & - \\
\hline$V_{b}$ & Battery voltage & 144 & V \\
\hline$v_{s}$ & DC bus voltage & 500 & V \\
\hline$\tau_{h 1}$ & Solenoid dead time & 0.02 & S \\
\hline$\tau_{h 2}$ & $\begin{array}{l}\text { Hydraulic circuitry } \\
\text { time delay }\end{array}$ & 0.06 & s \\
\hline $\mathrm{C}$ & Battery capacity & 8.1 & Ah \\
\hline$I_{\max }$ & Current vector limit & 300 & A \\
\hline$U_{\max }$ & $\begin{array}{l}\text { Duty cycle vector } \\
\text { limit }\end{array}$ & 0.5 & - \\
\hline$L_{d / q}$ & $\mathrm{~d} / q$ axis inductance & 0.58 & $\mathrm{mh}$ \\
\hline$P_{m}$ & Motor power & 15 & $\mathrm{Kw}$ \\
\hline
\end{tabular}

In the first case, the proposed MPC method is tested. In this test, different brake pedal displacements are tested. The brake pedal displacements are $40 \%, 60 \%$ and $80 \%$ of the maximum brake pedal displacement. The initial speed of vehicle is $30 \mathrm{~m} / \mathrm{s}$. This test is used to prove that the proposed MPC method is able to build the relationship between driver's brake intention and braking torque. The simulation results are shown in Fig.4. From Fig.4, it can be seen that the vehicle deceleration can be adjusted through adjusting the weight of MPC's cost function (42). From Fig. 4 , we can see that when the brake pedal displacement is large, the deceleration is fast. When the brake pedal displacement is small, the deceleration is slow. It meets the usual driving habits. This simulation result proves that proposed MPC method is able to properly build the relationship between driver's intention and braking torque.

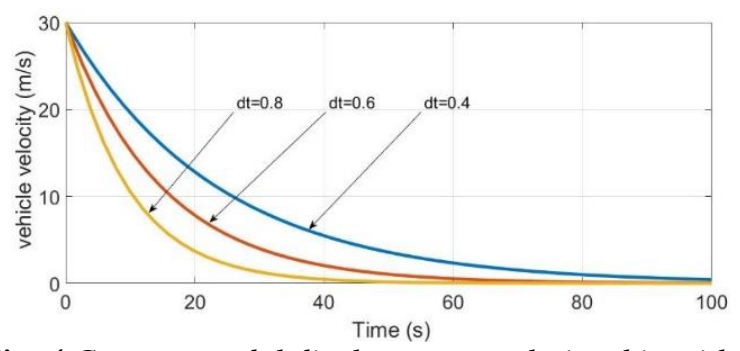

Fig. 4.Constant pedal displacements relationship with the vehicle speed. 
In order to further prove the proposed MPC method is able to reflect the driver's brake intention, another simulation is tested. In this test, the brake pedal displacement is a constant number ( $80 \%$ of the maximum brake pedal displacement) in the first $5 \mathrm{~s}$, then the brake pedal displacement starts to reduce. After $8 \mathrm{~s}$, the brake pedal displacement is 0 . The whole brake process is shown in Fig. 5(a). The red dotted line is used to simulate the driver's brake behavior. It means driver wants to make vehicle speed to slow down in the first $5 \mathrm{~s}$. When the vehicle speed is close to the desired speed, the driver starts to make brake pedal back to 0 displacement. Then the vehicle keeps running at the desired speed. The simulation result is shown in Fig. 5(a). Blue solid line is the vehicle speed. From the simulation results, we can see that vehicle can follow driver's brake intentions under the proposed MPC method. The vehicle speed decelerates at the first $5 \mathrm{~s}$. After $5 \mathrm{~s}$, the vehicle deceleration becomes smaller with the brake pedal displacement reduced. When the brake pedal displacement is 0 , the vehicle is able to keep running at a constant speed which is the desired speed. These simulation results show that the MPC is able to express driver's braking intentions and conforms to the driver's driving habits.

In the second case, the energy recovery is compared between different braking conditions at the normal braking situation. The initial speed of vehicle is $20 \mathrm{~m} / \mathrm{s}$. In this test, three situations are tested. Situation 1: the proposed MPC braking strategy is used. In this situation, brake pedal displacement is $50 \%$ of the maximum displacement at first 13s. Then driver takes further action and makes brake pedal displacement to $60 \%$ of the maximum displacement. According to the proposed MPC braking strategy, the vehicle deceleration should be $3 \mathrm{~m} / \mathrm{s}^{2}$. Situation 2 : the proposed MPC braking strategy is used. In this situation, brake pedal displacement is $50 \%$ of the maximum displacement, and the driver does not take any further action. The vehicle brake follows the proposed MPC braking strategy in the whole brake process. Situation 3: the conventional braking strategy is used. Normally, the vehicle brake deceleration is not greater than $2 \mathrm{~m} / \mathrm{s}^{2}$ in the case of normal braking. In this test, the vehicle brake deceleration is designed as $1 \mathrm{~m} / \mathrm{s}^{2}$.

The simulations results are shown in Fig. 5(b) and Fig. 5(c). Fig. 5(b) shows the energy recovery under different braking strategies and Fig.5(c) shows the brake distance under different brake strategies. Table 3 lists the summary of simulation results.

From Fig. 5(b), it can be seen that Situation 1 is same to Situation 2 at the first 13s. However, the energy recovery is different after $13 \mathrm{~s}$. The energy recovery is reduced after $13 \mathrm{~s}$ in Situation 1. It is because the driver takes further brake action after $13 \mathrm{~s}$ in Situation 1. It makes the vehicle deceleration with $3 \mathrm{~m} / \mathrm{s}^{2}$ and makes motor work at the plugging braking. In Situation 2, the proposed MPC makes motor work at the regenerative mode in the whole brake process. So the energy recovery is always increasing.

In order to make motor works at the regenerative mode, the proposed MPC method make vehicle deceleration small. So the brake distance is the longest in Situation 2. Brake distance under Situation 1 is almost same to the brake
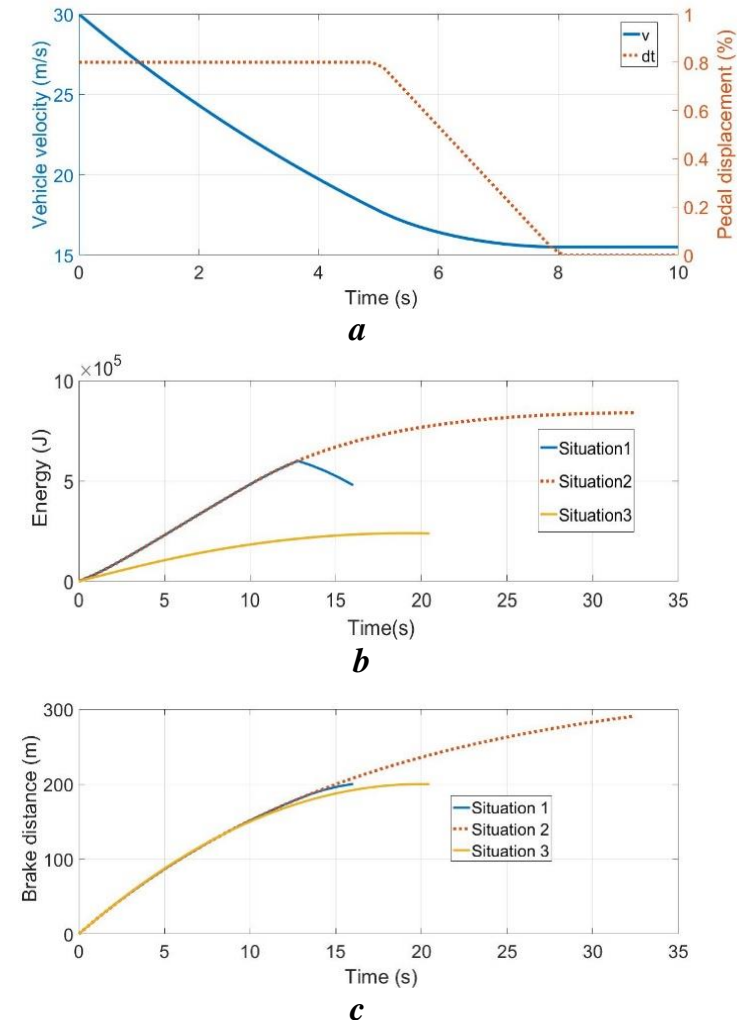

Fig. 5 vehicle normal braking test when initial speed of vehicle is $20 \mathrm{~m} / \mathrm{s}$. (a) Change pedal displacements relationship with the vehicle speed, (b) Energy recovery under different braking strategies in the case of the normal, braking, (c) Braking distance under different braking strategies in the case of the normal braking.

Table 3 Summary of test results in the case of normal braking condition.

\begin{tabular}{c|c|c|c}
\hline & Situation 1 & Situation 2 & Situation 3 \\
\hline $\begin{array}{c}\text { Energy } \\
\text { recovery } \\
(\mathrm{J})\end{array}$ & $4.78 * 10^{5}$ & $8.396 * 10^{5}$ & $2.361 * 10^{5}$ \\
\hline $\begin{array}{c}\text { Brake } \\
\text { distance } \\
(\mathrm{m})\end{array}$ & 200.2 & 290.6 & 199.9 \\
\hline
\end{tabular}

distance under Situation 3. It is because the vehicle deceleration is $3 \mathrm{~m} / \mathrm{s}^{2}$ after $13 \mathrm{~s}$ in Situation 1 . It is greater than the vehicle deceleration in Situation 3. It makes up the speed difference caused by the small deceleration at the first $13 \mathrm{~s}$.

The Situation 1 has almost the same braking distance with the Situation 3 (braking distance of Situation 1 is $200.2 \mathrm{~m}$ and braking distance of Situation 3 is $199.9 \mathrm{~m}$ as shown in Table 3). However, the Situation 1 recovers more energy than Situation 3 (as shown in Table 3). It proves that the proposed braking control strategy is able to recover more energy than normal braking control strategy with the same braking conditions (same initial braking speed, same terminal braking speed and same braking distance).The target of this proposed braking control strategy is to improve braking energy. It can be seen from Table 3 that Situation 2 recovers more energy than Situation 1 and Situation 3. The proposed braking control strategy is to recover more braking energy. As a price, the braking distance of Situation 2 is 
longer than the braking distance of Situation 1 and the braking distance of Situation 3.

In the case of emergency braking, the braking goal is also to make wheel slip ratio track the optimal slip ratio. It takes the sliding mode based optimal slip ratio control. For comparison,

a traditional blended braking system is used. It combines the regenerative brake (RBS) system and hydraulic brake (HBS) system. The RBS is same to the mentioned RBS in this paper. It is also composed of PMSM, bidirectional DC-DC, inverter and battery. The hydraulic braking is modelled with a first-order delay system with dead time [22]:

$\frac{T_{h b s}}{T_{h b s}^{*}}=\frac{e^{\tau_{h 1}}}{1+\tau_{h 2} s}$

where $\tau_{h 1}$ is the dead time of the solenoid; $\tau_{h 2}$ is the hydraulic circuitry time delay; $T_{h b s}^{*}$ is the command braking torque; $T_{h b s}$ is the output braking torque of HBS. The braking torque of RBS is designed as the difference between $T_{h b s}^{*}$ and $T_{h b s}$. In the real applications, the torque produced by HBS is hard to be measured. Many algorithms have been proposed to estimate the braking torque produced by mechanical brake [27] [28]. In this paper, the blended braking system is designed for comparison, thus it is assumed that the braking torque produced by HBS $T_{h b s}$ can be obtained. The command braking torque is also obtained by sliding mode control (Eq (51)).

Table 4 Summary of test results about braking distance in the case of emergency braking.

\begin{tabular}{ccc}
\hline $\begin{array}{c}\text { Brake } \\
\text { distance }(\mathrm{m})\end{array}$ & $\begin{array}{c}\text { Blended brake } \\
\text { system }\end{array}$ & $\begin{array}{c}\text { Electric brake } \\
\text { system }\end{array}$ \\
\hline $\begin{array}{c}\text { Initial } \\
\text { speed } 20 \mathrm{~m} / \mathrm{s}\end{array}$ & 54.74 & 54.92 \\
\hline $\begin{array}{c}\text { Initial } \\
\text { speed } 25 \mathrm{~m} / \mathrm{s}\end{array}$ & 85.59 & 86.24 \\
\hline $\begin{array}{c}\text { Initial speed } \\
33.33 \mathrm{~m} / \mathrm{s}\end{array}$ & 152.8 & 154.5 \\
\hline
\end{tabular}

Table 5 Summary of test results about energy recovery in the case of emergency braking.

\begin{tabular}{ccc}
\hline $\begin{array}{c}\text { energy } \\
\text { recovery }(\mathrm{J})\end{array}$ & $\begin{array}{c}\text { Blended brake } \\
\text { system }\end{array}$ & $\begin{array}{c}\text { Electric brake } \\
\text { system }\end{array}$ \\
\hline $\begin{array}{c}\text { Initial } \\
\text { speed } 20 \mathrm{~m} / \mathrm{s}\end{array}$ & $1.141 * 10^{4}$ & $1.124 * 10^{5}$ \\
\hline $\begin{array}{c}\text { Initial } \\
\text { speed } 25 \mathrm{~m} / \mathrm{s}\end{array}$ & $1.523 * 10^{4}$ & $2.5 * 10^{5}$ \\
\hline $\begin{array}{c}\text { Initial speed } \\
33.33 \mathrm{~m} / \mathrm{s}\end{array}$ & $1.948 * 10^{4}$ & $3.236 * 10^{5}$ \\
\hline
\end{tabular}

In the first test, the initial vehicle velocity is $20 \mathrm{~m} / \mathrm{s}$ and the optimal slip ratio is 0.2 . Pure electric braking system and blended braking system are tested to make vehicle stop in the case of emergency braking. The simulation results are shown in Fig. 6(a), Fig. 6(b), Fig. 6 (c) and Fig. 6 (d). And simulation results are listed in Table 4 and Table 5.

From Fig. 6(a), it can be seen that both the pure electric braking and blended braking systems are able to make wheel slip ratio follow the optimal slip ratio. However, the blend braking system is faster than the pure electric braking to track the optimal slip rate. This is because the maximum braking torque of blended braking system can provide is bigger than the maximum braking torque of pure electric braking can provide. This can be seen from Fig. 6 (c) and Fig. 6 (d). So the braking distance of blended braking system is shorter than the braking distance of pure electric
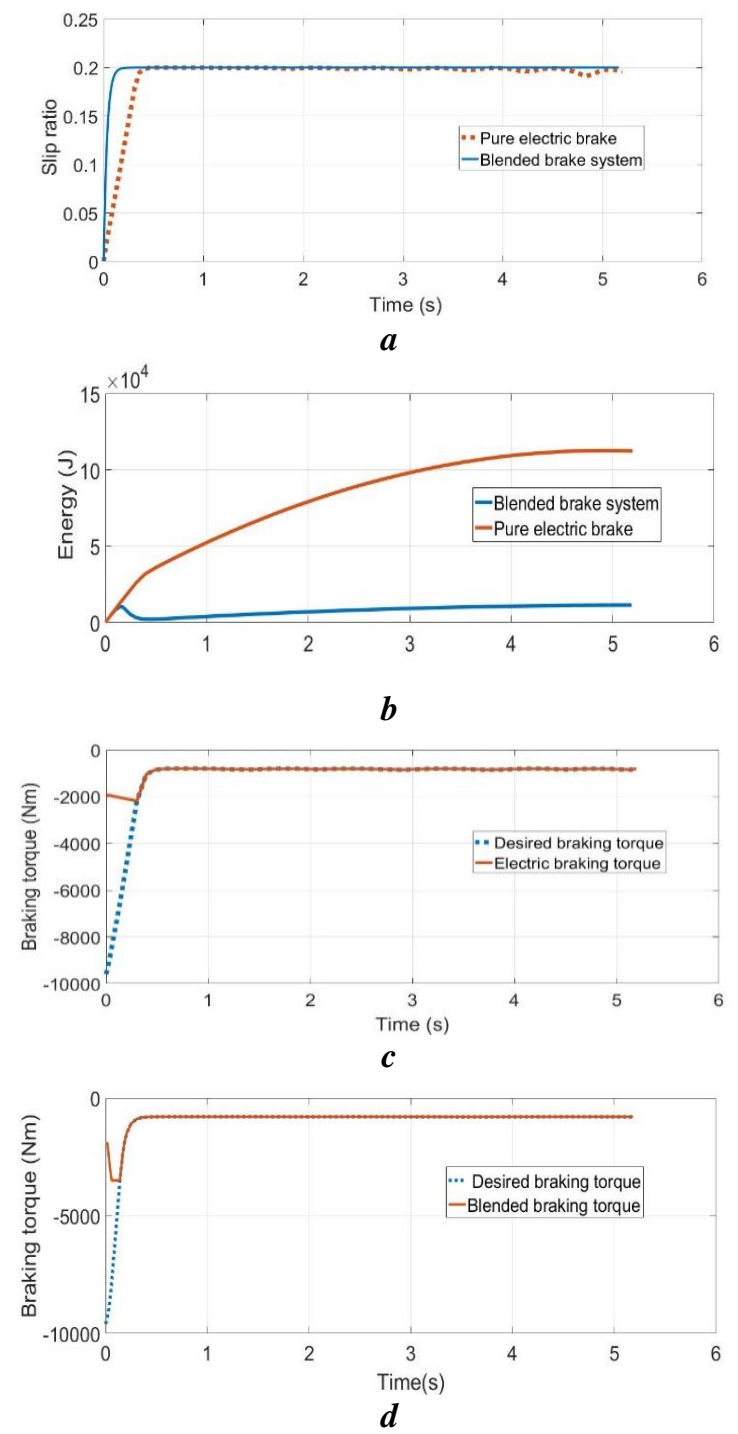

Fig. 6 vehicle emergency braking when the initial braking speed of vehicle is $20 \mathrm{~m} / \mathrm{s}$. (a) Slip ratio, (b) Recovery energy, (c) Braking torque of pure electric braking, (d) Braking torque of blended braking system.

braking. This can be seen from Table 4. However, the energy recovery of pure electric braking is far greater than the energy recovery of blended braking system. This can be seen from Fig. 6(b) and Table 5.

The braking torque is different with variation in vehicle speed in the initial stage of braking. This is because the motor speed is high in the initial stage of braking. It makes the motor work at constant power area. With the decreasing of vehicle speed, the maximum braking torque that motor can provide increases when the motor works at the constant power zone. So the braking torque is different with variation in vehicle speed in the initial stage of braking.

In the second test, the initial vehicle velocity is $25 \mathrm{~m} / \mathrm{s}$ and the optimal slip ratio is 0.2 . In the third test, the initial vehicle velocity is $33.33 \mathrm{~m} / \mathrm{s}$ and the optimal slip ratio is also 0.2. Pure electric braking system and blended braking 
system are tested to make vehicle stop in the case of emergency braking. The simulation results are shown in the Fig. 7 and Fig. 8. Simulation results are listed in Table 4 and Table 5.
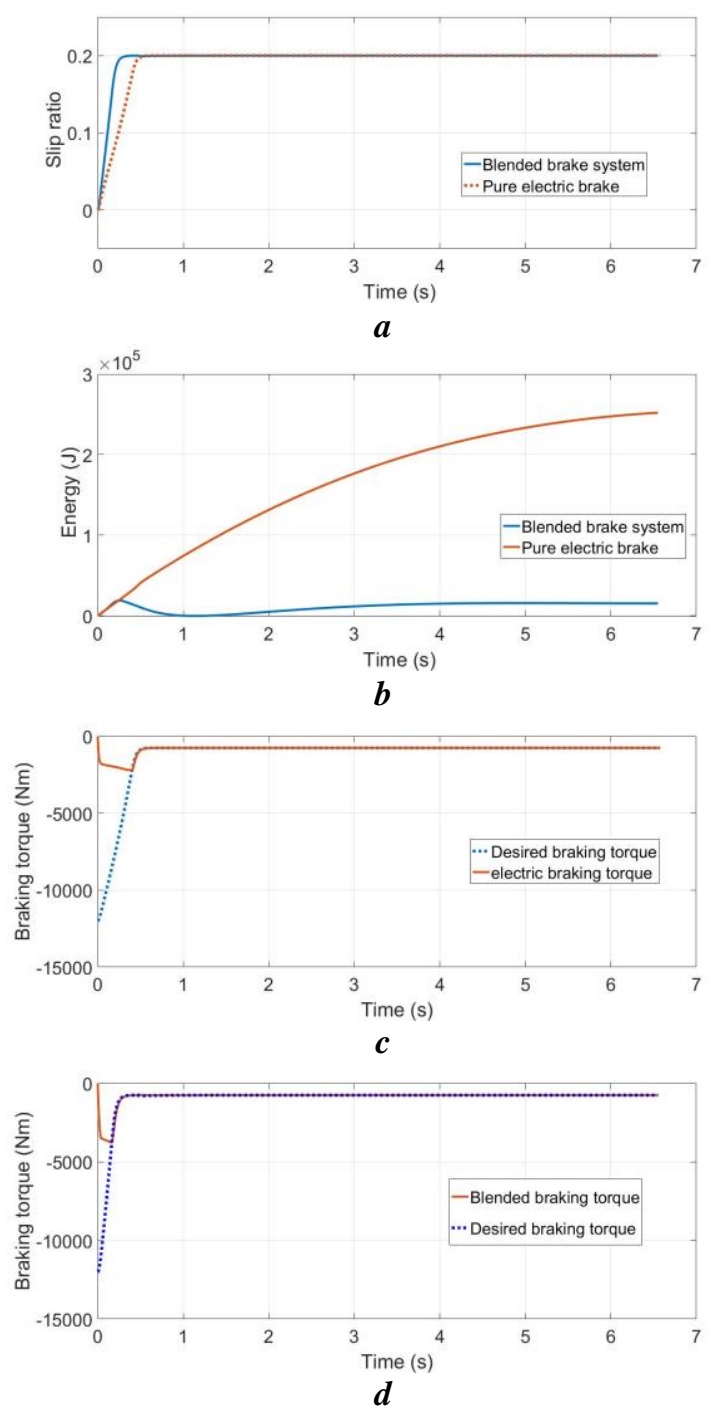

Fig. 7 vehicle emergency braking when the initial braking speed of vehicle is $25 \mathrm{~m} / \mathrm{s}$. (a) Slip ratio, (b) Recovery energy, (c) Braking torque of pure electric braking, (d) Braking torque of blended braking system.

From Fig. 7(a) and Fig. 8 (a), it can be seen that both the pure electric braking and blend braking systems are able to make wheel slip ratio follow the optimal slip ratio. Compared to Fig. 6(a), the optimal slip ratio tracking performance of Fig. 7(a) is slower. Compared to Fig. 7(a), the optimal slip ratio tracking performance of Fig. 8(a) is slower. Because the maximum braking torque of pure electric braking can provide becomes smaller when the initial speed of vehicle is faster (it can be seen from the Fig. 2(b)), it makes the optimal slip ratio tracking speed slow. The energy recovery of pure electric braking is far greater than the energy recovery of blended braking system. This can be seen from Fig. 6 (b), Fig. 7 (b), Fig. 8 (b) and Table 5. From Table 4 and Table 5, it can be seen that the pure electric braking is able to recycle far more energy than the blended braking system. As a price, the braking performance of pure electric braking is less than the braking performance of blended braking system. It also can be seen that the difference between pure electric braking and blended braking system decreases with the initial braking speed of vehicle decreasing.

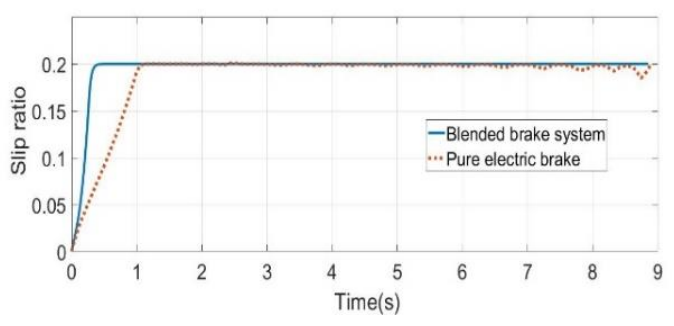

$\boldsymbol{a}$

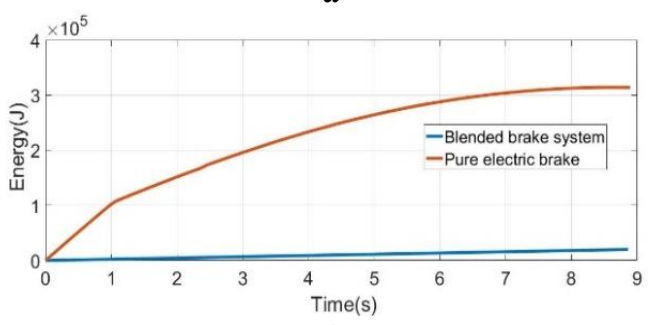

$\boldsymbol{b}$

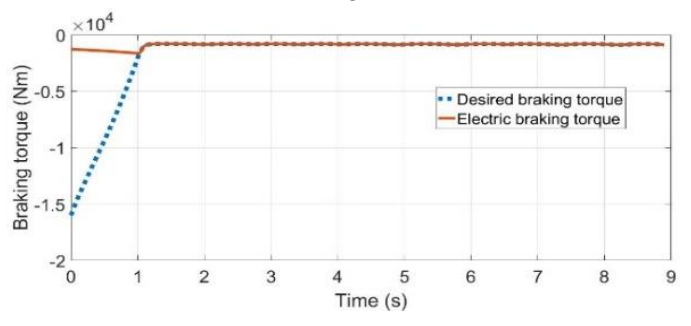

c

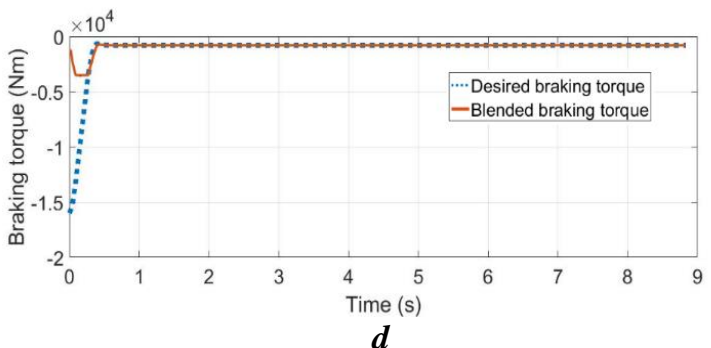

Fig. 8 vehicle emergency braking when the initial braking speed of vehicle is $33.33 \mathrm{~m} / \mathrm{s}$. (a) Slip ratio, (b) Recovery energy, (c) Braking torque of pure electric braking, (d) Braking torque of blended braking system.

\section{Conclusion}

In this paper, the braking characteristics of motor is analyzed. The maximum regenerative braking torque of PMSM is used as constraint for MPC design and the relationship between driver's braking intentions and braking torque is built. The proposed MPC braking strategy is tested in the cases of emergency braking and normal braking. The simulation results show that the proposed MPC braking strategy is able to follow the driver's braking intention and is able to recycle more energy than the conventional braking strategy at normal braking condition. In the case of emergency braking, the proposed pure electric braking is able to recycle more energy than the blended braking system. It is able to have similar braking performance between the proposed pure electric braking and blended braking system when the initial speed of vehicle is at low to middle range. 
ACKNOWLEDGEMENT- This research was supported under Australian Research Council's Discovery Projects funding scheme (project number DP140100303).

\section{References}

[1] Juliane, H., Amila K., Ralf, R.: 'Role of driver assistance experience, system functionality, gender, age and sensation seeking in attitudes towards the safety of driver assistance systems', IET Intelligent Transport Systems., 2015, 9, (7), pp. $716-726$.

[2] Zhen, W., John, X., Dunant, H.: 'Braking force control strategy for electric vehicles with load variation and wheel slip considerations', IET Electrical Systems in Transportation., 2017, 7, (1), pp. $41-47$.

[3]Antony, M., R.S Praveen, R.:'Four Quadrant Operation of Vector Control of PMSM with dynamic braking', Control Communication \& Computing India (ICCC) 2015 International Conference on, Trivandrum, Kerala, India, Nov 2015, pp 161-164.

[4]Bian, Y., Lijing, Z., Hao, L. et al: 'Regenerative braking strategy for motor hoist by ultracapacitor', Chinese Journal of Mechanical Engineering., 2012, 25, (2), pp 377-84.

[5]Dinçmen, E., Bilin, A.:'A control strategy for parallel hybrid electric vehicles based on extremum seeking', Vehicle System Dynamics, 2012, 50,(2), pp 199-227.

[6]Han, C., Ziming, Q., Hao, Q., and Tao, P.: 'Test platform design for regenerative braking of hub-motor', Cogent Engineering., 2016, 3, pp 1-8.

[7]Hongxing, W., Li, L., Bao-quan K., Ping, Z.:'The Research on Energy Regeneration of Permanent Magnet Synchronous Motor Used for Hybrid Electric Vehicle', IEEE Vehicle Power and Propulsion Conference (VPPC), November 2008, Harbin, China.

[8]Jing, G., Minggao, O., Jianqiu, L., Dongbin, L., Chuan, F., and MA, Y.: 'Driving and Braking Control of PM Synchronous Motor Based on Lowresolution Hall Sensor for Battery Electric Vehicle', Chinese Journal of Mechanical Engineering., 2013, 26, (1), pp 1-10.

[9]Joice, C., Sheeba, S., Paranjothi, R., and V, J.: 'Digital Control Strategy for Four Quadrant Operation of Three Phase BLDC Motor With Load Variations', IEEE Transactions on Industrial Informatics., 2013, 9, (2), pp 97482.

[10]Kim, D., Jung-Hyo, L., An-Yeol, K., Chung-Yuen, W., and Young-Ryul, K.: 'Braking Torque Control Method of IPMSM for Electric Vehicle Using 2D Look-up Table', Industrial Electronics (ISIE), 2013 IEEE International Symposium on, Taipei, Taiwan, May 2013.

[11] Liang, L., Xujian, L, Xiangyu, W., Yahui, L, Jian, S., and $\mathrm{Xu}, \mathrm{R}$.: 'Transient switching control strategy from regenerative braking to anti-lock braking with a semi-brakeby-wire system', Vehicle System Dynamics., 2016, 54, (2), pp 231-257.

[12]Yufeng, Lian., Yun, Z., Leilei, H., and Yantao T.:'Longitudinal Collision Avoidance Control of Electric Vehicles Based on a New Safety Distance Model and Constrained-Regenerative-Braking-Strength-Continuity

Braking Force Distribution Strategy', IEEE Transactions on Vehicular Technology., 2016, 65, (6), pp.4079-4094.

[13]Long, B., Shin, L., Ji, R., and Kil, C.:'EnergyRegenerative Braking Control of Electric Vehicles Using
Three-Phase Brushless Direct-Current Motors', Energies, 2014, 7, pp.99-114.

[14]Ming-Ji, Y., Jhou, H., Ma, B., and Shyu, K.:'A CostEffective Method of Electric Brake With Energy Regeneration for Electric Vehicles', IEEE Transactions on Industrial Electronics., 2009, 56, (6), pp. 2203-2212.

[15] Nam, Myung, J., Kwan, Y., Hag Wone $\mathrm{K}$ et al.:'Braking Algorithm Considering Voltage Limit Condition for Surface Mounted PM SynchronousMotor', 18th international conference on electrical machines and systems (ICEMS), pattaya city, Thailaand, Oct 2015.

[16] Farshid, N., Ebrahim, F., Teymoor, G.:'An Efficient Regenerative Braking System Based on Battery/Supercapacitor for Electric, Hybrid and Plug-In Hybrid Electric Vehicles with BLDC Motor', IEEE Transactions on Vehicular Technology., 2017, 66, (5), pp.3724-3738.

[17]obed, Adel A., Ali, K., Abdulabbas, and Ahmed, J. Chasib.:'Plugging Braking of Two-PMSM Drive in Subway Applications with Fault -Tolerant Operation', Iraq J. Electrical and Electronic Engineering., 2016,12,(1),pp.1 12.

[18]Pagano, E., Veneri, O.:'Regenerative motor and plug braking operations of electrical drives for road vehicles', COMPEL - The international journal for computation and mathematics in electrical and electronic engineering., 2002, 21, (1),pp.58 -68.

[19]Ning, Q., Xuan, D., Y, Kim.:'Modeling and control strategy development for fuel cell hybird vehicles', international Journal of automotive technology., 2010, 11, (2), pp.229-238.

[20] M, Ye., Z, Bai., B, Cao.: 'Robust control for regenerative braking of battery electric vehicle', IET Control Theory \& Applications., 2008, 2, (12), pp.1105-1114.

[21]Yuan, L., Haiyan, Z., Hong, C., and Bingtao, R.:'Nonlinear MPC-based slip control for electric vehicles with vehicle safety constraints', Mechatronics., 2016, 38, (12),pp.1-15.

[22] Atev, S., Arumugam, H., Masoud, O., et al.: 'A visionbased approach to collision prediction at traffic intersections', IEEE Trans. Intell. Transp. Syst., 2005, 6, (4), pp. 416-423

[23] Wang, P., Wang, J., Chan, C., et al.: 'Trajectory prediction for turning vehicles at intersections by fusing vehicle dynamics and driver's future input estimation', Transp. Res. Rec., 2016, 2602, pp. 68-77.

[24] Shladover, S., Tan, S.: 'Analysis of vehicle positioning accuracy requirements for communication-based cooperative collision warning', J. Intell. Transp. Syst.: Tech. Plann. Oper., 2006, 10, (3), pp. 131-140.

[25] Tan, H., Huang, J.: 'DGPS-based vehicle-to-vehicle cooperative collision warning: engineering feasibility viewpoints', IEEE Trans. Intell. Transp. Syst., 2006, 7, (4), pp. 415-428.

[26] Zhou, Xinxiu, and Jiancheng Fang.:'Precise Braking Torque Control for Attitude Control Flywheel With Small Inductance Brushless DC Motor', IEEE Transactions on Power Electronics., 2013, 28, (11), pp.5380-5390.

[27] Chihoon, J., Sungho, H., Hyunsoo, Kim.: 'ClampingForce Control for Electromechanical Brake,' IEEE Transactions on Vehicular technology., 2010, 59, (7), pp: 3205-3212. 
[28] Javier, F., Matthew, A., Karolos, G.: 'Real-time brake torque estimation for internal combustion engines', Mechanical Systems and Signal Processing 22 (2008) pp: 338-361. 